\title{
Ciências sociais e intelectualidade: ciência, educação e política
}

Lívia Bocalon Pires de Moraes'

\section{Resumo}

0 artigo busca compreender as relações entre ciências sociais, análise sociológica e planejamento da educação pública escolar no Brasil, especialmente quanto à atuação de alguns cientistas sociais Fernando de Azevedo, Anísio Teixeira, Florestan Fernandes e Darcy Ribeiro - visando à constituição e a modernização do país por meio da intervenção racional da intelectualidade na esfera estatal. Para isso, discute a noção de intelectual e a atuação de parte desse grupo social no Brasil, em diferentes momentos históricos, destacando a função social que atribuiam a si em cada contexto e a primazia que conferiam à educação formal como possibilidade de constituição de um novo país. Destaca as ações de Anísio Teixeira e Fernando de Azevedo, suas concepções acerca da sociologia e a educação, seu envolvimento com a Escola Nova e com a legislação educacional, e sua influência no pensamento e no trabalho intelectual e político de Florestan Fernandes e Darcy Ribeiro. Discute a compreensão desses dois autores acerca da função social do intelectual e da sociologia, seu envolvimento com a educação pública por meio de movimentos como a Campanha pela Defesa da Escola Pública, de cargos públicos na área educacional e da atuação político-partidária, e aponta similaridades, como a defesa da obrigatoriedade da escola pública, laica e gratuita, diante da diversidade de projetos e de pontos de vista concebidos por cada um eles. Aborda, por fim, o contexto institucional recente das ciências sociais no Brasil e os limites e possibilidades que essa condição oferece ao seu envolvimento com a questão educacional.

\section{Palavras-chave}

Fernando de Azevedo - Anísio Teixeira - Florestan Fernandes Darcy Ribeiro - Educação pública escolar.

I- Universidade Estadual Paulista Júlio de Mesquita Filho - UNESP, Araraquara, SP, Brasil. Contato: libocalon@hotmail.com 


\title{
Social sciences and intelligentsia: science, education and politics
}

Lívia Bocalon Pires de Moraes

\begin{abstract}
The article intends to understand the relations between social sciences, sociological analysis and the planning of public school education in Brazil, especially regarding the actions of some social scientists - Fernando de Azevedo, Anisio Teixeira, Florestan Fernandes, and Darcy Ribeiro -, aiming to constitute and modernize the country through the rational intervention of the intelligentsia in the state level. To do so, it discusses the notion of intellectual and the actions of part of this social group in Brazil, at different historical moments, highlighting the social function they attributed to themselves in each context and the primacy they gave to formal education as a possibility of constitution of a new country. It highlights the actions of Anisio Teixeira and Fernando de Azevedo, their conceptions of sociology and education, their involvement with Escola Nova movement and with educational legislation, and their influence on the thought and intellectual and political work of Florestan Fernandes and Darcy Ribeiro. It discusses the two authors' understanding of the social function of intellectuals and sociology, their engagement in public education by means of movements such as the Campaign in Defense of Public School, public positions in the educational area and political party work, and points out similarities, such as the defense of compulsory, public, secular, free school, given the diversity of projects and points of view of each one of them. Finally, it discusses the recent institutional context of social sciences in Brazil and the limits and possibilities that this condition offers to their involvement with the educational issue.
\end{abstract}

\section{Keywords}

Fernando de Azevedo - Anísio Teixeira - Florestan Fernandes Darcy Ribeiro - Public school education.

I- Universidade Estadual Paulista Júlio de Mesquita Filho (UNESP), Araraquara, SP, Brasil. Contact: libocalon@hotmail.com 


\section{Introdução}

Os intelectuais, para a maioria dos especialistas, são uma categoria social surgida por ocasião do Caso Dreyfus, por ter sido nessa circunstância que o termo começou a ser utilizado como rótulo no debate público (LECLERC, 2004). A noção de intelectual, desde então, tem sido muito utilizada no ambiente acadêmico-científıco, em especial nas ciências sociais, e a amplitude de seu uso acarreta certas dificuldades aos que pretendem conceituá-la, posto que o termo pode ser abordado conforme diferentes referenciais teórico-metodológicos.

Para Sartre (1994), por exemplo, os intelectuais são recrutados dentre os técnicos do saber prático, responsáveis pelo exame crítico do campo dos possíveis e cuja formação técnica e ideológica define-se por um sistema constituído de cima e de forma classista, que os torna agentes de um particularismo ideológico, enquanto sua prática se funda no humanismo e no universalismo, sofrendo uma constante contradição. Diante dessa realidade, tais técnicos podem constituirse como intelectuais. A partir da tomada de consciência de sua contradição, que é também o desvelamento das contradições dos conflitos de classe e da disparidade entre a verdade da classe dominante e os meios utilizados para garantir sua hegemonia, o intelectual vêse impelido a se engajar nos conflitos de seu tempo, realizando uma autocrítica permanente, por reconhecer-se enquanto agente histórico que não conhece o porvir, mas se faz, por ser um homem-contradição, o "guardião dos fins fundamentais” (SARTRE, 1994, p. 52).

$\mathrm{Na}$ conceituação de Gramsci (2001) está presente um conceito ampliado de intelectual, que tem como critério o sistema de relações em que as atividades intelectivas são desempenhadas, sendo estas analisadas na totalidade das classes sociais em que são desenvolvidas. Seria possível dizer que "todos os homens são intelectuais, mas nem todos os homens têm na sociedade a função de intelectuais" (GRAMSCI, 2001, v. 2, p. 18). Esses distinguem-se por realizarem certas tarefas relativas à organização da cultura e de outras dimensões da vida em sociedade e por contribuírem para reproduzir ou transformar a ordem social, fornecendo consciência e homogeneidade às classes que representam, ao produzirem ideologia.

A consciência dessa distinção, de acordo com Lahuerta (1998), acirrou-se entre os intelectuais após a 2a Guerra Mundial, em função da reflexão sistemática acerca de suas condições de existência e da tendência a se pensarem como um estrato social definido e apartado da sociedade, em especial onde a modernização foi vivenciada como projeto de construção da nação e de superação do atraso, em que há um ideal genérico de progresso e desenvolvimento, que atribui à intelligentsia um papel fundamental.

No Brasil, os intelectuais desempenharam um papel muito relevante como figuras de articulação política e social, em face da sociedade civil debilmente constituída. Assim, a abolição da escravatura, a proclamação da República e a posterior transição do sistema de produção agrário para o capitalismo industrial teriam contribuído para a ampliação das produções no campo cultural e para a valorização da fıgura do intelectual, em oposição ao trabalho manual, desprezado como resultado da tradição escravista (MARTINS, 1987).

Para Martins, nesse momento os intelectuais defendiam a república no contexto de reformas institucionais políticas e sociais vagamente definidas, concebendo-a como a chave capaz de abrir o sistema político a novos atores, e reivindicando a liderança moral da nação, sem conseguirem pensar em uma nova sociedade. Mais que esta, a construção da nação constituía seu principal eixo de preocupação, tarefa que atribuíam a si, enquanto heróis civilizadores, e que seria realizada por intermédio do Estado.

A intelectualidade, nesse momento, girava em torno do Estado ou era parte dele, 
inclusive os cientistas sociais, que tinham como papel extrair do social os fundamentos da formação estatal, e conferir legitimidade à sua ação, direcionada para civilizar a sociedade atrasada. Por conseguinte, "A inteligência, inclusive a confessional, especializa-se em si mesma, e, longe do povo, auto interdita-se para assumir papéis de reforma social". (VIANNA, 1997, p. 203).

Constitui-se em exceção parte da intelectualidade brasileira que, durante as décadas de 1920 e 1930, teve na educação do povo pela instrução pública, na reforma do ensino e na construção de um campo cultural uma via para a ação, inclusive junto ao Estado, associando a reforma da sociedade à reforma do ensino, que realizaria simultaneamente a criação de cidadãos e a modernização das elites, o que seria "uma dessas ideias recorrentes no Brasil, como também em outras partes" (MARTINS, 1987, p. 15).

Desse modo, no país, o campo pedagógico tende a se autonomizar patrocinado por elites que atribuem a si mesmas a tarefa de modernizar a sociedade, e que percebem a educação como alavanca da modernidade, utilizando-se de conceitos como nacionalismo, democracia, progresso e industrialização para nortear a ordem social, empregando o saber científico, acompanhado de traços elitistas e da reivindicação de maior intervenção estatal, para legitimar as exigências da inserção do povo, saído da barbárie, na civilização, e da formação da nacionalidade através da constituição de uma cultura nacional.

Nesse contexto, conforme Pinto; Leal; Pimentel (2000), a reconstrução do ethos racional do discurso pedagógico da modernidade se fez a partir da incorporação dos fundamentos científicos das ciências sociais, através da atuação de importantes cientistas sociais que intervieram signifıcativamente na esfera estatal, em especial quanto à educação pública escolar.

Dentre esses cientistas, pela relevância de seus empreendimentos, destacam-se Fernando de Azevedo e Anísio Teixeira. Fernando de Azevedo foi professor de sociologia no Instituto de Educação da Universidade de São Paulo e catedrático do Departamento de Sociologia e Antropologia da Faculdade de Filosofia, Ciências e Letras da mesma universidade, em que foi professor emérito. Foi também redator e crítico literário do jornal 0 Estado de São Paulo e diretor geral da Instrução pública do Distrito Federal, onde realizou reformas profundas no sistema de ensino. Presidiu a Associação Brasileira Nacional e, posteriormente, foi diretor da Faculdade de Filosofia, Ciências e Letras de São Paulo, além de secretário da Educação e Saúde do estado de São Paulo; diretor e organizador do Centro Regional de Pesquisas Educacionais; fundador e diretor da Biblioteca Pedagógica Brasileira na Companhia Editora Nacional e um dos fundadores da Sociedade Brasileira de Sociologia, que presidiu.

Anísio Teixeira foi inspetor-geral do ensino na Bahia; diretor da Instrução Pública do Distrito Federal e secretário da Educação do Rio de Janeiro, estado onde empreendeu uma ampla reforma na rede de ensino; fundador da Universidade do Distrito Federal, depois transformada em Faculdade Nacional de Filosofia da Universidade do Brasil; conselheiro geral da Organização das Nações Unidas para Educação, a Ciência e a Cultura - UNESCO e secretário-geral da Educação na Bahia, além de criador e primeiro dirigente da Campanha de Aperfeiçoamento do Ensino Superior - CAPES e diretor do Instituto Nacional de Estudos Pedagógicos - INEP. Foi um dos fundadores da Universidade de Brasília e seu reitor, atuando também como tradutor dos trabalhos de John Dewey, professor nas universidades de Columbia e na Califórnia, e consultor da Fundação Getúlio Vargas.

0 exercício de diversos cargos executivos por esses dois intelectuais não foi sua única maneira de ação relativamente às políticas públicas direcionadas à educação formal, e tampouco a fonte exclusiva da legitimidade adquirida por eles e pelas ciências sociais nos 
campos educacional, científico e político no período. Para compreender a influência de ambos nas relações entre educação e sociologia, é necessário analisar suas concepções teóricas e a inspiração mútua que exerceram em suas obras e pontos de vista, em especial no trabalho que realizaram coletivamente por meio do Movimento dos Pioneiros da Educação Nova.

\section{Fernando de Azevedo e Anísio Teixeira: ao povo e ao governo}

No início do período republicano, o emprego do voto de cabresto para a manutenção do poder político dos setores oligárquicos gerou um divórcio entre a classe política e a elite intelectual, motivando parte desta última a constituir o chamado grupo do Estado, que reunia jornalistas, intelectuais e políticos em torno do jornal 0 Estado de São Paulo, que tinha como uma de suas preocupações a erradicação do analfabetismo, com o objetivo de sanar os problemas do baixo censo eleitoral e do peso da massa inculta nas decisões do país.

Com vistas a esses propósitos, o grupo encomendou a Fernando de Azevedo um inquérito sobre a educação pública no estado de São Paulo, em que o autor aponta como principal problema a falta de uma política de educação clara e completa para formar elites intelectuais, que seriam as únicas capazes de orientar um projeto político e social da formação da nacionalidade. Azevedo, para Totti (2009), entendia que a abertura da elite governante à entrada de indivíduos superiores dos estratos mais baixos, por meio da educação, criaria na consciência popular uma ideia de mobilidade social, sendo necessário consolidar e estender a todos a educação pública, gratuita, e financiada pelo Estado, para que das massas se extraíssem novos membros da elite. Dessa forma a educação popular e a formação das elites seriam dois aspectos indissociáveis do mesmo projeto.

Com base nessas concepções surgiu o projeto da criação da Universidade de São
Paulo, objetivando a construção de um padrão científico na educação brasileira, por meio do qual se formaria uma elite dirigente para romper com os padrões oligárquicos e servir de guia seguro para a democracia no país, orientando os sentidos da nação através do estudo científico dos grandes problemas nacionais, no que a sociologia teria função fundamental.

Além do desenvolvimento da sociologia na universidade, a imparcialidade e a neutralidade são componentes marcantes no pensamento de Azevedo, que buscava dar moldes científicos aos estudos educacionais, compreendendo a sociologia como a:

[...] ciência da sociedade e das realidades sociais, (que) tem por fim, antes de tudo, como qualquer outra ciência, descobrir a verdade por meio da observação das relações de causa e efeito no mundo objetivo (TOTTI, 2009, p. 71).

Assim, o correto direcionamento da educação exigia o emprego da sociologia, posto que aquela é um fenômeno social, um fato social, coletivo, que exerceria pressão no indivíduo, e teria seu fator coletivo sujeito à diversidade, manifestando-se no interior de cada grupo social. Sendo a sociologia a ciência base da educação, todo educador deveria ter consciência da natureza sociológica do fenômeno educacional e de sua relação com os demais fenômenos coletivos. As finalidades da educação seriam definidas a partir de um ponto de vista sociológico, pois através da ciência, da coerência administrativa e organizacional, e da racionalização de procedimentos, seria possível conceber uma saída para a crise educacional brasileira, com vistas à implementação da modernidade.

Teixeira compartilhava da noção de que a educação progressiva teria que responder às profundas alterações no contexto da vida social, sendo necessário à escola preparar homens capazes de se integrar rapidamente na civilização baseada na ciência e na tecnologia, 
aparelhando as crianças para uma atitude crítica e cidadã.

Em viagem realizada em 1927 aos Estados Unidos, o educador tomou contato com as teorias de John Dewey e da Escola de Chicago, tornando-se um democrata convicto e um entusiasta do sistema norte-americano de organização da sociedade, admirando principalmente a extensão da educação pública ao conjunto da população (BOMENY, 2001a). Ele entendia que era tarefa do Estado conduzir e garantir a implementação de uma reforma que respondesse à precariedade do nosso sistema educacional, e que democratizasse a educação segundo o princípio de reconhecimento da inteligência do senso comum. Criticava profundamente o modelo escolar tradicional e a defesa de uma razão absoluta, generalizante e formal, opondo a ela uma razão flexível e relativa, assim como a escola. Para tal, seria necessário o aporte sociológico, posto que o próprio Anísio jamais desvinculava a educação de processos sociais mais amplos e avaliava que esta teria sentido se e na proporção em que estivesse sociologicamente fundada.

0 início do trabalho conjunto dos dois cientistas, na década de 1920, se deu em resposta à atuação das Ligas de Defesa Nacional, que, diante do reconhecimento da precariedade educacional, associaram a alfabetização em massa da população à resolução espontânea de todas as demais mazelas que afetavam a maioria da sociedade brasileira. Este ocorreu através da criação da Associação Brasileira de Educação (ABE), que reuniu educadores dispersos pelo país, como Heitor Lira, Antônio Carneiro Leão e Delgado de Carvalho, com o objetivo de influir na implantação de políticas públicas para a educação, embasando-se em teorias filosóficas, sociológicas e psicológicas europeias e norte-americanas. Tais intelectuais guiavam-se, de acordo com Bomeny (2001), pela crença iluminista de transformar mentalidades pelo projeto reformador da Associação, comprometendo-se em solucionar o problema educacional.
Para tal, organizavam diversos congressos, entre eles a IV Conferência Nacional de Educação, que teve como tema as grandes diretrizes da educação popular (GHIRALDELLI JR, 2006) e a V Conferência Nacional de Educação, em 1932, cujo objetivo foi a discussão de um Plano Nacional de Educação, em que diversos jovens intelectuais assinaram o Manifesto dos Pioneiros da Educação Nova, escrito por Azevedo durante o evento. 0 documento, com o subtítulo $A$ reconstrução educacional do Brasil - ao povo e ao governo, surgiu na imprensa como um manifesto público que representava as aspirações do grupo e suas posições políticas, como o produto de um movimento organizado de educadores profissionais que tinham como norteamento uma leitura científica, política e social da educação, percebendo-a em uma sociedade em transformação, a qual necessitava urgentemente da construção de um Estado-nação, a ser produzido através da reconstrução educacional.

0 manifesto representa a tomada de consciência, por esses intelectuais, da necessidade de se adequar a educação ao tipo de sociedade e à forma assumida pelo desenvolvimento brasileiro da época, envolvendo propostas que ultrapassavam o campo específico da pedagogia tradicional. Para os signatários, o maior problema educacional do país era a insuficiência de planos do governo, aos quais faltariam uma filosofia da educação e a visão científica das questões educacionais, sendo necessário empregá-las, para retirar a escola e os programas de ensino da situação de segregação social imperante no Brasil (GHIRALDELLI JR, 2006).

A educação nova deveria pautar as finalidades da educação para além dos limites de classe e promover a hierarquia democrática, baseada nas capacidades individuais, reconhecendo a todos o direito biológico de serem educados até onde permitissem suas aptidões naturais, independente de possíveis limitações econômicas e sociais. Para que esse direito fosse garantido, seria necessário que a escola tradicional fosse superada, 
concretizando-se através de escolas laicas, gratuitas, de ensino obrigatório e onde fossem igualmente educadas crianças de ambos os sexos, cabendo ao Estado implantar a chamada escola única, tornando a educação acessível, em todos os seus graus, a todos os cidadãos, o que não implicaria que este fosse o detentor do monopólio da educação.

Esses princípios estão presentes também em outro documento da Associação, $O$ problema educacional e a nova Constituição, publicado em 1934 como anteprojeto do capítulo sobre educação para a Constituição Nacional. Nele, Azevedo e Teixeira, junto dos demais Pioneiros da Escola Nova, afırmam que a educação deveria ser democrática, humana e geral, laica e gratuita, oferecendo a todos os brasileiros as mesmas oportunidades de educação e destinando-as à formação integral do homem e do cidadão, sem restrições de ordem econômica, social, religiosa ou doutrinária (GHIRALDELLI JR, 2006).

A tomada de posição por parte do movimento renovador, face aos representantes da escola tradicional, teve consequências práticas na elaboração do texto da Constituição de 1934, em que o Capítulo II representa, em sua quase totalidade, uma vitória desse movimento, determinando a educação como direito de todos, e dever do poder público e da família a garantia de acesso a ela (ROMANELLI, 1985). Poucos anos depois, com a instauração do Estado Novo e de uma nova Constituição, em 1937, o tema da educação foi tratado de modo mais restrito, retirando-se do texto constitucional a ênfase antes conferida ao dever do Estado como educador, ainda que mantendo a gratuidade e obrigatoriedade do ensino, o que segundo a autora constitui-se como influência do mesmo movimento.

Fica claro que, embora vinculados a matrizes teóricas diferentes, Azevedo e Teixeira partilhavam da convicção da necessidade de uma reforma educacional no país, promovida pelo Estado, que estendesse a toda a população o direito à educação, bem como da importância de que essa formasse cidadãos aptos às transformações constitutivas de uma sociedade moderna, contribuindo para a promoção da ordem democrática.

Bomeny (2001) afırma que outro traço em comum desses educadores é a crença de que, em sua missão de intelectuais formadores poderiam, pela educação, salvar o Brasil. A autora também destaca que a proximidade entre eles seria motivada pelo debate de filosofias e teorias da educação que implicaram reflexões sobre suas próprias posições, com vistas a aprimorá-las.

Ambos influenciaram dois outros intelectuais que, cada um a seu modo, deram continuidade à intervenção pública dos cientistas sociais na análise e planejamento do sistema educacional no Brasil. Florestan Fernandes é apontado por Pinto; Leal; Pimentel (2000) como discípulo, numa linha de ruptura radical, de Fernando de Azevedo, a convite de quem o cientista iniciou sua carreira docente na Universidade de São Paulo, enquanto Darcy Ribeiro é considerado pelas autoras o continuador das ideias de Anísio Teixeira, sob cuja influência o antropólogo perseguiu uma agenda pública de intervenção na política educacional brasileira, em sintonia e adesão confessa ao Movimento da Escola Nova.

\section{Darcy Ribeiro e Florestan}

Fernandes: em defesa da escola pública

No final da década de 1940, o contexto pós-guerra promoveu a legitimação da demanda por benefícios educacionais a maiores segmentos da população, em função do aumento da requisição de participação política e social, aliado ao oferecimento de mais condições para a ampliação do campo cultural e ao retorno da experiência democrática, que aumentou a pressão pela melhoria das condições de vida e de acesso às políticas públicas. Dessa maneira, o Brasil, na década de 50, se tornou uma espécie de laboratório para experimentos de democratização e mobilização política, e de experimentação de propostas educativas, envolvendo expressões renovadas no campo da literatura, música, artes plásticas, poesia, bem 
como a criação do Movimento de Educação de Base, dos Centros Populares de Cultura, e dos Movimentos de Cultura Popular, que teriam buscado, pela ótica da elite intelectual, a constituição de uma identidade nacional.

Para Mota (1977), os anos 50 teriam se iniciado com uma radicalização interpretativa da situação brasileira, de modo que a superação do subdesenvolvimento se tornou um objetivo vago, a ser conquistado de forma planejada, promovendo a alteração da situação nacional pela saída da periferia rumo à condição de centro. Essa concepção seria acompanhada por certo otimismo, motivado pela visão de que, promovendo-se as circunstâncias conjunturais e estruturais favoráveis à mudança, a América Latina não mais seria um continente subdesenvolvido.

De acordo com Mazza (1997), os intelectuais desse período teriam continuado a vocação herdada dos anos 30 de se apresentarem como categoria social específica que teria um papel decisivo nas mudanças políticas, manifestando como novidade a relação que teriam estabelecido com o povo, eleito como sujeito social da vida brasileira. Pécault (1990) também destaca a concepção dos intelectuais a respeito de sua vocação para conduzir a nação ao encontro de si mesma, invocando em gerações sucessivas a realidade nacional como justificativa de sua intervenção, persuadidos de que estavam de expressarem o que é de fato o social e o que é de fato o desenvolvimento, em especial na década de 1950.

Nessa época, de acordo com Vianna (1997), os cientistas sociais que, no período de institucionalização da sociologia no Brasil, estavam isolados dos seres subalternos e de seus problemas, constituem-se em comunidade científica e convertem-se em uma intelligentsia, investindo-se da vocação de reforma social ao institucionalizarem-se como comunidade científica, buscando compreender cientificamente o sentido do movimento da sociedade e generalizar seu conhecimento aos demais atores políticos e sociais. Desse modo, as ciências sociais se consagraram publicamente como provedoras de orientação metodológica e norteadoras da intervenção nas esferas públicas da política, educação, administração e economia, inscrevendo-se na vida pública, em torno de uma agenda de reformas sociais, e mantendo-se como campo adequado ao desempenho da missão intelectual de esclarecimento para a busca de projetos de transformação.

Para o autor, o caráter distintivo desse grupo seria dado por sua condição de cientistas sociais, que, supostamente, os credenciaria como intérpretes legitimados pela ciência no sentido de diagnosticar problemas e prever soluções. Segundo Pécault (1990), devido ao hiato entre o social e o político, os intelectuais teriam se tornado mediadores indispensáveis, articulando-se constantemente com o Estado enquanto intérpretes das massas populares, de modo que sua tarefa política seria a de ajudar o povo a tomar consciência de seu papel revolucionário, demonstrando que o desenvolvimento econômico, a emancipação das classes populares e a independência nacional seriam três aspectos do mesmo projeto.

Nesse sentido, ao assumir um papel estratégico na construção de um projeto nacional, a educação deu à sociologia a oportunidade de exercer sua primazia entre as ciências sociais, tendo sido alvo de diversas pesquisas na área entre as décadas de 1940 e 1960, o que contribuiu para a afırmação desta como conhecimento válido de caráter científico, que deu conteúdo intelectual e legitimidade acadêmica aos reclamos populares, ao tratar de questões como a oferta educacional a partir de uma dimensão predominantemente social.

A atuação de Florestan e Darcy é expressiva do contexto em que a realizaram, posto que, para ambos, a relação entre as ciências sociais e a educação é indissociável, assim como o é o papel do cientista social, como intelectual, e a tarefa de intervir, a partir dessa condição, nos rumos dessa esfera da sociedade.

Os dois pertencem à primeira geração de cientistas sociais brasileiros profissionalizados 
e com formação universitária específica, sendo Darcy formado pela Escola Livre de Sociologia e Política, cuja finalidade técnica consistia em fornecer sociologicamente bases racionais para a organização da vida moderna, e Florestan pela Faculdade de Filosofia e Ciências da Universidade de São Paulo, caracterizada pelo esforço de descrever, analisar e interpretar a realidade brasileira a partir de uma forma de participação que se situava fortemente na contribuição que o intelectual poderia dar à construção da ordem social igualitária, sem deixar de ser intelectual e enquanto intelectual.

Logo, a concepção do trabalho intelectual, para Florestan, exige que a consciência de seu papel social se baseie na necessidade de denunciar os obstáculos socioculturais ao desenvolvimento nacional, contribuindo, através da produção científıca, para as exigências da sociedade.

A interpretação darcyniana de intelectual, por outro lado, para Bomeny (2001a), atribui a ele o talento em desvendar o enigma social, ao qual deve ser agregado o sentido da missão transformadora, mantendo-se o autor como intelectual ao mesmo tempo em que recusava o ethos acadêmico, considerando indissociáveis a atividade intelectual e o engajamento político.

Dessa forma, ainda segundo a autora, Darcy via a si mesmo e queria ser visto como um homem do povo, um intelectual engajado e comprometido com um sentido de nacionalidade de forte conteúdo romântico-popular, como realizador de um projeto e dotado de uma missão pública, o qual tinha a crença sincera de ser portador de características intransferíveis capazes de conduzir a coletividade para a melhor direção.

A atividade pública do autor atribui destaque para a defesa dos direitos sociais, com realce para um projeto de Estado orientado conforme princípios de igualdade e capaz de incluir e integrar a massa da população ao conjunto da sociedade beneficiária das riquezas socialmente disponíveis, adotando a educação como área de atuação definitiva como intelectual público, que teve como projeto de vida intervir nos processos políticos alterando seu curso.

Portanto, apesar de para Pinto; Leal; Pimentel (2000) não ser possível detectar a presença de uma sociologia da educação no pensamento de Darcy Ribeiro, sua ação é dotada de uma visão social da educação que assume o sentido de denúncia política, reatualizando o movimento escolanovista e conferindo:

[...] à agenda da Escola Nova o conteúdo popular e de massa que a elite dos renovadores não pretendeu, não se mobilizou ou não pôde fazê-lo para implementar (BOMENY, 2001, p. 76-77).

0 pensamento de Florestan Fernandes (1966), por outro lado, expressa sua perspectiva política na defınição de uma função social ao conhecimento sociológico, ao qual atribui um papel ativo, na forma de sociologia aplicada. Consequentemente, o interesse da contribuição sociológica ao desenvolvimento social está presente na definição dos alvos da pesquisa, sendo fundamental para o autor que os cientistas sociais, com base na cooperação interdisciplinar, atribuam soluções racionais e empreguem a noção de ciência aplicada como fator racional para a mudança social provocada.

Florestan, que tem como preocupação estrutural a busca dos fundamentos da sociedade brasileira, vê o cientista social como um profissional indispensável ao desenvolvimento social e econômico do país, constituindo-se em elo entre as ciências e os saberes do cotidiano, e colocando a razão ordenadora da sociologia a serviço da educação das massas em direção à consciência e capacidade de transformação. Dessa maneira, o dilema educacional brasileiro se configura como campo do qual esses cientistas poderiam participar intelectualmente, tendo como propósito estabelecer culturalmente alvos e modelos racionais de ação.

A sociologia da educação, nessa visão, é uma forma de interpretar e conhecer 
os problemas educacionais que tem como referência sua dinâmica no contexto social, ocupando-se das relações entre os processos educacionais e o conjunto de instituições que os transformam ou mantêm a ordem social (PINTO; LEAL; PIMENTEL, 2000). A educação, por conseguinte, é reclamada como técnica social capaz de instrumentalizar a sociedade brasileira para a prosperidade e o progresso da nação, adaptar os indivíduos às exigências da vida social democrática e preparar o cidadão para a vida econômica, política e social. Ela não se constituía, assim, em chave para a solução imediata dos problemas nacionais, mas em meio significativo de conscientização, cuja concretização dependia da intervenção estatal mais eficaz na melhoria e expansão da rede de ensino.

Com o intuito de aplicar os conhecimentos das ciências sociais ao planejamento educacional, com o apoio da UNESCO, foi criado o Centro Brasileiro de Pesquisas Educacionais (CBPE), idealizado por Teixeira com o duplo objetivo de apoiar o desenvolvimento das ciências sociais e estimular cientistas sociais a se interessarem pelo estudo dos problemas educacionais. A contribuição do Centro para o cruzamento entre ciências sociais e educação foi fundamental, constituindo-se este em

[...] ponto de encontro das duas gerações de intelectuais (pioneiros da escola nova e jovens cientistas sociais - Florestan, Darcy, Cardoso, Ianni) e palco de combate da disputa de projetos diferenciados de Estado via educação (XAVIER apud DIAS DA SILVA, 2002, p. 117).

Para a formação intelectual de Darcy Ribeiro o CBPE também foi essencial, pois foi através dele que o cientista estabeleceu o primeiro contato com Anísio Teixeira, que o convidou para coordenar a Divisão de Estudos e Pesquisas Sociais (Deps) do Centro. Nela, o conceito de educação era entendido como socialização, extrapolando ou por vezes ignorando o conceito de educação escolar, de modo que o foco da produção era atribuído às pesquisas mais gerais sobre a realidade brasileira, acarretando a perda da centralidade intelectual do tema educacional, o que fez com que o órgão exercesse mais impacto no desenvolvimento das ciências sociais do que nas pesquisas educacionais.

Essa realidade, segundo Dias da Silva (2002), gerou problemas quanto ao ideal da relação entre teoria e prática. A elite de educadores do Centro muitas vezes entrava em conflito com os professores ou educadores mais ligados à prática, que não possuiam a formação teórica valorizada pelos primeiros, de modo que a necessidade de afirmação do caráter teórico-científico das ciências sociais e o caráter aplicado da educação provocavam tensões. Na perspectiva dos professores, as pesquisas do CBPE eram muito acadêmicas, e não respondiam aos anseios práticos, por realizarem debates com teorias sociológicas e processos mais gerais em detrimento de pesquisas voltadas para o planejamento e reforma do sistema educacional brasileiro.

A interferência de cientistas sociais quanto às decisões relativas ao direcionamento de nosso sistema de ensino, todavia, não se deu fundamentalmente através das referidas pesquisas. Entre as décadas de 1940 e 1960, esses participaram das lutas referentes às definições da Lei de Diretrizes e Bases. 0 movimento buscava garantir ao sistema nacional de educação um caráter orgânico e integrado, submetendo-o a um conjunto de objetivos comuns e a um mínimo de princípios diretores fundamentais, e teve na figura de Anísio Teixeira, novamente, um importante defensor, em oposição aos representantes da Igreja Católica, que defendiam os interesses das escolas privadas e a descentralização do sistema educacional.

Além de Teixeira, Azevedo também fez parte da liderança do movimento, redigindo o Manifesto dos educadores mais uma vez convocados, que invocava as ideias do Manifesto dos Pioneiros da Educação Nova ao mesmo tempo em conferia destaque ao aspecto social da educação, aos deveres do Estado 
democrático e à imperiosa necessidade de que esse cuidasse não só da sobrevivência da escola pública, mas efetivamente a assegurasse a todos. Além dos dois pioneiros, Florestan Fernandes também se tornou uma liderança combativa da Campanha de Defesa pela Escola Pública, cujos objetivos ele redigiu.

Assim, a campanha tornou-se um movimento de opinião pública em torno dos problemas educacionais comparável apenas ao realizado pelos defensores da escola nova. Dele participaram outros cientistas sociais, entre os quais Darcy Ribeiro, convocados por Florestan a apontarem aos educadores os pontos de estrangulamento e os fatores de inércia das instituições escolares brasileiras e a contribuírem para o esclarecimento do homem comum sobre a situação de nosso sistema educacional, assumindo para si, desse modo, o dever de colocar os conhecimentos sociológicos a serviço da reconstrução social, e compreendendo-se como vanguarda na consciência dos problemas sociais.

As opiniões a respeito do resultado final do processo, com a promulgação da Lei 4.024/61, refletiram as posições dos grupos envolvidos, indo desde o otimismo dos privatistas ao pessimismo de seus opositores. Anísio Teixeira considerou-a como "meia vitória, mas vitória", resultante da solução intermediária dada pelo Congresso aos extremos do projeto inicial e do substitutivo Carlos Lacerda, representante dos interesses dos privatistas, enquanto para Florestan a aprovação do projeto foi uma derrota popular.

Apesar de não atingir os resultados desejados, a Campanha em Defesa pela Escola Pública teve como consequência a popularização crescente da figura de Florestan, devido a seu contato direto com sindicatos de trabalhadores, movimento estudantil e entidades organizadas da sociedade civil, além de entrevistas em rádios e artigos jornalísticos. Um ano depois da aprovação da lei, em uma série de artigos em que retoma criticamente sua participação no movimento, buscando incorporar sociologicamente as lições tiradas dessa experiência, o autor a destaca como exemplo bem-sucedido de comunicação entre sociólogos e grande público. Após a campanha, a orientação teórica de Florestan tornou-se mais marcadamente marxista, produzindo pesquisas acerca das relações de classes, a especificidade dos modos de produção no Brasil e a precariedade de nossa sociedade burguesa, e buscando identificar os mecanismos sociais que impossibilitaram a realização da ordem democrática no Brasil.

A intervenção militar em 1964, de acordo com Vianna (1997), pela restrição geral às liberdades, demissão de professores e identificação das ciências sociais como subversivas, produziu o enfraquecimento da posição de seus departamentos no sistema universitário, interditando o acesso dessa intelligentsia, na universidade ou fora dela, à comunicação com a sociedade. Além disso, o próprio processo de modernização autoritária do capitalismo brasileiro demonstrou que as referências sociológicas acerca da oposição atraso-moderno e a consequente proeminência do segundo mediante à afırmação da democratização, dos direitos e da cidadania, mostravam-se anacrônicas, posto que neste o moderno e a modernização tinham seu curso sem contraposições políticas com a sociedade tradicional e com o atraso.

0 viés economicista do golpe concebia que mudanças econômicas em sentido modernizante provocariam a indução de um desenvolvimento político e social homólogo à sua natureza, favorecendo a assimetria entre as esferas política, econômica e social, pois compreendia a modernização como conclusão do processo de imposição do capitalismo, que tinha no uso da violência política o expediente para sua concretização.

Devido a essa visão, a dimensão do social não se apresentava como dotada de legitimidade própria, devendo ser organizada por cima, o que teve como consequência o não reconhecimento de um objeto preferencial 
à sociologia, bem como a não atribuição aos intelectuais da tarefa de produzir ideologias em sua estratégia de reprodução, uma vez que a forma de legitimação do regime se dava pelo desempenho econômico.

A isso se deve, majoritariamente, a preservação da identidade elaborada nas décadas anteriores para as ciências sociais institucionalizadas que, subestimadas, não sofreram a ameaça de disputarem sua supremacia com uma orientação alternativa, nos anos de chumbo da ditadura, de forma a conseguirem se dedicar corporativamente à reprodução de sua atividade, garantindo a sua clientela ao afrouxarem seus critérios de seleção e seus padrões curriculares. Nas palavras de Vianna (1997, p. 221).

Marginalizadas e sem se confrontar com uma concorrência à sua tradição, resistiram à escassez de recursos, à censura, às demissões e ao exílio de seus professores, zelando por seu patrimônio intelectual.

Dessa maneira, quando sob a gestão de Ernesto Geisel foi criado um sistema de políticas públicas para favorecer a internalização da ciência moderna no país, as ciências sociais encontravam-se institucionalmente credenciadas para receberem recursos das agências de fomento à pesquisa, experienciando o paradoxo de terem intensificada sua institucionalização sob o regime militar, que era indiferente, quando não inteiramente hostil, à sua produção. A principal forma de resposta dos cientistas sociais ao novo regime se deu fora da universidade, em revistas de opinião e através de sua inserção nos movimentos de intelectuais que denunciavam os atentados à liberdade cometidos pelo governo, o que reforçou nesse grupo o sentimento de que seriam portadores de um mandato público, de acordo com a ideia de intelligentsia construída anteriormente ao regime.

Florestan e Darcy também sofreram os efeitos da relação do regime militar com as ciências sociais. 0 primeiro foi aposentado compulsoriamente da cadeira de sociologia da USP devido ao AI-5 da ditadura militar, exilando-se no Canadá, onde trabalhou como professor titular na Universidade de Toronto, retornando ao Brasil em 1973, onde permaneceu proibido de lecionar. 0 segundo havia sido ministro da Educação no governo de Jânio Quadros, em 1961, e exercia a chefia da Casa Civil, em que coordenava a implantação das reformas estruturais, quando ocorreu o golpe, que cassou seus direitos políticos e o exilou. Viveu em diversos países da América Latina, atuando como assessor dos presidentes Salvador Allende, no Chile, e Velasco Alvarado, no Peru, retornando ao Brasil em 1976 e dedicando-se novamente à educação e à política.

A militância político-partidária, embora já fosse vivenciada pelos dois intelectuais, só se evidenciou em seus discursos nos anos 80, após o retorno do regime político brasileiro ao pluripartidarismo. Florestan filiou-se ao Partido dos Trabalhadores (PT) em 1986, ano em que foi eleito Deputado Constituinte pelo partido, tendo atuação destacada nos debates sobre a educação pública e gratuita, e Darcy elegeuse vice-governador do Rio de Janeiro, junto com Leonel Brizola, em 1982, pelo Partido Democrático Trabalhista (PDT). No partido, empregando a política como artífice na busca por alternativas mais justas e adequadas à realidade nacional, o antropólogo transformou a educação de objeto sociológico de investigação, responsável por problemas estruturais de nosso subdesenvolvimento, em área a ser reformada, criando para tal os Centros Integrados de Educação Pública (CIEPs), um programa de escolas de educação integral direcionado prioritariamente para as classes populares residentes na periferia, e que tinha como ambição promover a instrução, desenvolvimento de artes e ciências, assistência alimentar, médica e odontológica e iniciação ao trabalho, constituindo-se em um programa integral de civilização e de educação para a vida.

Darcy Ribeiro tornou-se senador pelo Rio de Janeiro em 1991, enquanto Florestan havia se reelegido no ano anterior como 
deputado federal. Ambos se envolveram no processo decisório que teria como resultante a Nova Lei de Diretrizes e Bases da Educação Nacional, fruto de uma intensa luta parlamentar e extraparlamentar. Entidades da sociedade civil, detentoras de interesses diversos, porém convergentes a respeito da defesa do ensino público e gratuito, se reuniram em momentos distintos e contribuíram para a criação de diferentes versões da LDB. Florestan e Darcy também foram signatários de ideais e projetos divergentes quanto à lei, o primeiro coordenando o Grupo de Trabalho da LDB na Câmara, que por meio de Conselhos de caráter deliberativo unindo as autoridades governamentais e a comunidade educacional deu início ao projeto na Câmara dos Deputados, e o segundo como redator do projeto no Senado, que preponderou na articulação aquele advindo da Câmara, resultando na redação final da Lei de Diretrizes e Bases.

\section{Considerações finais}

Diante das trajetórias de Fernando de Azevedo, Anísio Teixeira, Florestan Fernandes e Darcy Ribeiro - e do esforço para compreender os contextos em que estas se efetuaram relativamente à constituição de um campo cultural no Brasil, que simultaneamente exercia influência e era permeado pela busca da construção do próprio país, e conferindo especial atenção ao processo de institucionalização das ciências sociais e às relações estabelecidas por seus praticantes entre sua formação enquanto cientistas sociais e sua ação enquanto intelectuais, cabe efetuar a análise de modo a traçar algumas similaridades entre elas.

A atribuição ao Estado da responsabilidade de efetivação da educação, compreendida como instrumental racional indispensável para o constante aperfeiçoamento do homem e da sociedade, manifestando-se na forma de escola pública, advém do pensamento liberal e iluminista, logo, da sociedade capitalista moderna. Todavia, de acordo com Pinto; Leal; Pimentel, a realidade histórica brasileira, por ser marcada pela incipiente organização da sociedade civil e por uma sociedade de classes tendente a privatizar o espaço e os recursos públicos em favor de seus polos dominantes, se mostrou incapaz de levar adiante um processo de autogestão do sistema educacional, o que produz a necessidade de se afırmar as obrigações do Estado no que se refere à educação pública escolar.

Desse modo, os cientistas sociais citados adotam a educação escolar como meio prioritário de superação das carências do Brasil, definidas pela comparação com países desenvolvidos, elaborando construções coletivas, ainda que balizadas por matrizes que podem ser diferenciadas:

[...] acerca da ação e do papel do Estado na elaboração e no controle de um sistema nacional de ensino, da relação público versus privado e do compromisso que a nação deveria assumir perante o ensino público (PINTO; LEAL; PIMENTEL, 2000, p. 40).

Estes se concebem, perante essa realidade, como integrantes de uma categoria social específica, dotada da responsabilidade, vocação, missão, tarefa, ou liderança moral, de conduzir a nação ao encontro de si mesma, construir a nação, modernizar a sociedade, civilizar o povo inculto, salvar o Brasil, superar o atraso, superar o subdesenvolvimento, ajudar o povo a tomar consciência de seu papel revolucionário, ou conduzir a coletividade para a melhor direção.

Os intelectuais estudados, ao atribuírem a si a tarefa de intervir na realidade social, em especial no que diz respeito ao direcionamento e organização do sistema nacional de ensino, adotaram as ciências sociais como norteamento científico e racional da ação, responsável por direcionar e definir não apenas a atuação dos cientistas sociais, mas também de educadores, professores, e do próprio Estado. Dessa forma, eles teriam como características comuns 
a crença na racionalidade e no poder das ideias, por pensarem serem capazes de, por meio do planejamento baseado na ideologia, no projeto ou na consciência, sustentados sociologicamente, modificarem a realidade. (PÉCAULT, 1990).

Motivados por essa concepção, esses intelectuais atuaram como organizadores da cultura e do campo educacional na sociedade civil, tematizando a reorganização do Estado nacional pela promoção de um amplo debate político em torno das questões ligadas à unidade, organização nacional, modernização institucional e incorporação de novos setores sociais, transitando e ocupando espaços institucionalmente estratégicos, como a ABE, o CBPE, a imprensa, a universidade e os partidos políticos. Assim, embora também atuassem individualmente enquanto cientistas, professores e homens públicos, todos eles, em maior ou menor grau, envolveram-se como lideranças em movimentos coletivos, que tiveram como norteamento uma leitura científıca, política e social da educação.

Dessa maneira, tendo em vista que a educação no Brasil não tem sido matéria de Estado, mas de governo, o que dificulta a continuidade das políticas implementadas, e que, como afirma Romanelli (1985), a organização do ensino foi imposta pelas várias facções das camadas dominantes das estruturas de poder, fazendo com que a legislação do ensino evoluísse de forma contraditória, as consequências práticas da atuação de Teixeira, Azevedo, Florestan e Darcy mostram-se muito importantes, tendo influenciado, em maior ou menor medida conforme o contexto, a legislação vigente sobre o ensino, nas Constituições de 1934, 1937 e 1988, e nas Leis de Diretrizes e Bases da Educação de 1961 e 1997.

Por esse motivo, o gradativo reconhecimento da legitimidade, e mesmo da primazia das ciências sociais junto ao público e ao Estado, enquanto orientadoras da ação racional e planejada, em especial anteriormente ao regime militar, se deve em grande parte à sua relação com o direcionamento das políticas públicas voltadas à educação formal, por meio da organização e planejamento do sistema nacional de ensino.

Estas, segundo Vianna (1997), tornaram-se, após a redemocratização, ciências cada vez mais institucionalizadas e especializadas, o que deixa pouco espaço para que seus integrantes constituam uma intelligentsia de tipo manheimiano, de modo que passam a ser os laboratórios, departamentos universitários e centros de pesquisa que desempenham o papel de agências de intelectuais orientados para a mudança social provocada. Devido às mudanças históricas e sociais relativas ao aprofundamento da vida política e social, os cientistas sociais brasileiros não mais têm diante de si uma sociedade que demande uma ação pedagógica em favor do moderno, ou que permita que eles atuem como substitutos legítimos das elites ou dos partidos.

Para o autor a situação das ciências sociais, nesse contexto, é de transição de um modelo aristocrático para um modelo democrático, caracterizado pela americanização da área, em que as produções científicas abrangem objetos fragmentários (a mulher, o negro, os movimentos sociais etc.) com os quais os cientistas se identificam como autores e a partir dos quais se inscrevem na vida pública, assumindo simultaneamente sua representação no plano científico e na prática dos movimentos sociais que encarnam os temas. Estes, diferente dos fundadores da disciplina, não possuem um mandato público que permite que se dirijam à sociedade como seus intelectuais, portadores de sua razão crítica ou intérpretes gerais de seu movimento, o que os torna menos inclinados a portarem-se como membros de uma intelligentsia tradicional, e configura um novo padrão de relacionamento entre os cientistas sociais e a vida pública, de modo que sua inscrição nela:

[...] assume uma entonação minimalista, legitimadora de interesses, de fragmentos de interesses, colada ao seu específico objeto social e às suas demandas por autonomia e reconhecimento social (VIANNA, 1997, p. 230). 
Isso traz como risco a perversão corporativa em torno de pequenos objetos. Assim, as ciências sociais podem ser destituídas de sua relevância social e científica, se compostas por uma comunidade científica encerrada em si mesma e aplicada em extrair recursos das políticas públicas para sua autoreprodução, ou podem ter como resultado a inovação, especializando-se conjuntamente a seu processo de institucionalização, mas sem abdicar de seu impulso originário para que se encontrem com sua sociedade, continuando a atuar, entre outras vias, através da pesquisa e planejamento voltados à educação pública, sociologicamente fundados.

\section{Referências}

BOMENY, Helena. Darcy Ribeiro: sociologia de um indisciplinado. Belo Horizonte: UFMG, 2001a.

BOMENY, Helena. Os intelectuais da educação. Rio de Janeiro: Jorge Zahar, 2001.

DIAS DA SILVA, Graziela M. Sociologia da sociologia da educação: caminhos e desafios de uma policy science no Brasil (19201979). Bragança Paulista: Edusf, 2002.

FERNANDES, Florestan. Educação e sociedade no Brasil. São Paulo: Dominus: Edusp, 1966.

GHIRALDELLI JR., Paulo. História da educação brasileira. 2. ed. São Paulo: Cortez, 2006.

GRAMSCI, Antonio. Cadernos do cárcere. Rio de Janeiro: Civilização Brasileira, 2001.

LAHUERTA, Milton. Gramsci e os intelectuais: entre clérigos, populistas e revolucionários (modernização e anticapitalismo). In: LAHUERTA, Milton; AGGIO, Alberto (Org.). Gramsci: a vitalidade de um pensamento. São Paulo: Edunesp, 1998. p. 133-158.

LECLERC, Gérard. Sociologia dos intelectuais. São Leopoldo: Unisinos, 2004.

MARTINS, Luciano. A gênese de uma intelligentsia: os intelectuais e a política no Brasil, 1920-1940. Revista Brasileira de Ciências Sociais, São Paulo, v. 2, n. 4, p. 65-87, jun. 1987.

MAZZA, Débora. A produção sociológica de Florestan Fernandes e a problemática educacional: uma leitura (1945-1964). 1997. Tese (Doutorado em Sociologia) - Universidade Estadual de Campinas, Campinas, 1997.

MOTA, Carlos G. Ideologia da cultura brasileira (1933-1974). São Paulo: Ática, 1977.

PÉCAULT, Daniel. Os intelectuais e a política no Brasil: entre o povo e a nação. Tradução de Maria Júlia Goldwasser. São Paulo: Ática, 1990.

PINTO, Diana; LEAL, Maria C.; PIMENTEL, Marília (Org.). Trajetórias de liberais e radicais pela educação pública. São Paulo: Loyola, 2000.

ROMANELLI, Otaíza de Oliveira. História da educação no Brasil (1930-1973). Petrópolis: Vozes, 1978.

SARTRE, Jean-Paul. Em defesa dos intelectuais. São Paulo: Ática, 1994.

TOTTI, Marcelo Augusto. Ciência e educação no pensamento de Alberto Torres, Fernando de Azevedo e Florestan Fernandes: das rupturas paradigmáticas à análise retórica. 2009. 151 f. Tese (Doutorado em Educação Escolar) - Faculdade de Ciências e Letras da Universidade Júlio de Mesquita Filho, Araraquara, 2009.

VIANNA, Luiz Werneck. A revolução passiva: iberismo e americanismo no Brasil. Rio de Janeiro: Revan, 1997.

Recebido em: 18.09.2014

Aprovado em: 10.03.2015

Lívia Bocalon Pires de Moraes é mestra em ciências sociais pela Faculdade de Ciências e Letras de Araraquara (FCLAr - UNESP), onde desenvolve a pesquisa intitulada Representando disputas, disputando representações: cientistas sociais e campo acadêmico no ensino de sociologia, com financiamento do Conselho Nacional de Desenvolvimento Científico e Tecnológico (CNPq). 